\title{
SRH needs of Syrian refugees in Jordan nine years post crisis: with emphasis on MISP implementation and transition into comprehensive SRH services
}

Mirwais Amiri ( $\square$ mamiri@alumni.emory.edu )

EMPHNET: Eastern Mediterranean Public Health Network https://orcid.org/0000-0002-5842-6739

Mohannad Al Nsour

EMPHNET: Eastern Mediterranean Public Health Network

Enas Alaloul

EMPHNET: Eastern Mediterranean Public Health Network

Tala Chahien

EMPHNET: Eastern Mediterranean Public Health Network

Loulou Hassan Kobeissi

WHO: Organisation mondiale de la Sante

\section{Research Article}

Keywords: (Sexual and) Reproductive Health, Minimum Initial Service Package, Syrian Refugees, Syrian Crisis, Humanitarian Settings

Posted Date: April 5th, 2022

DOI: https://doi.org/10.21203/rs.3.rs-1074032/v2

License: (1) This work is licensed under a Creative Commons Attribution 4.0 International License. Read Full License 


\section{Abstract}

\section{Background:}

Millions of Syrians have been forcibly displaced since March 2011. Most of them live in neighbouring countries, including Jordan, with adolescent girls and women as the most vulnerable populations. After almost nine years of the protracted crisis, it was essential to examine available evidence around the effectiveness of MISP/SRH interventions implemented for them in Jordan to inform the humanitarian community and the government by identifying best practices, essential gaps, bottlenecks, and lessons learnt.

\section{Methods:}

Using a previously validated MISP/SRH survey tool and combining quantitative and qualitative research methods, an assessment was conducted in 2018 in four governorates of Jordan to evaluate the availability of MISP/SRH interventions/programs. Data were obtained by trained data collectors and analyzed in SPSS-IBM.

\section{Results:}

Overall, 58 key informants (KIs) from 15 different entities/agencies participated in the assessment. $\mathrm{KIs} /$ respondents had various levels of knowledge/sources of information about the MISP/SRH services and had variable engagement in implementation. The results of this assessment highlighted significant knowledge gaps about the implementation of MISP objectives and priorities, even after almost nine years of the onset of the crisis. Among different MISP activities, family planning, maternal health, condom distribution, and newborn health services had the highest level of preparation and implementation, while availability of antiretrovirals (ARVs) for prevention of mother-to-child transmission (PMTCT) and access to safe blood had the lowest level of preparation and implementation. This assessment also showed lack of national coordination in the provision of different SRH services, lack of a national plan for capacity building, and lack of adequate logistics support systems and funding.

\section{Conclusions:}

Important gaps in the knowledge and implementation of MISP/SRH activities continue to exist in Jordan almost nine years into the Syrian displacement. Areas in need of focus include: national coordination in the provision of SRH services, a national plan for capacity building, logistics support systems, and funding for MISP/SRH services provision. Additional funding needs include: Capacity building of service providers with focus on training activities around different MISP/SRH services, facilitating emergency preparedness, improving coordination, and improving referral systems.

\section{Background}


By the end of 2020, according to UNHCR, 82,4 million individuals were estimated to be forcibly displaced, among which more than a quarter (26.4 million) were refugees, either under the United Nations High Commissioner for Refugees' (UNHCR's) or the United Nations Relief and Works Agency's (UNRWA's) mandates [1]. Approximately, 34 million of forcibly displaced people were adolescent girls and women of the reproductive age [1]. The Syrian crisis is one of the most recent refugee crisis in the Middle East (ME) [2]. Syria, one of the top three countries under the UNHCR mandate of displaced population, has about 6.7 million refugees who have been forcibly displaced since $2011[1,3]$.

Humanitarian crisis exacerbates the vulnerability of adolescent girls and women, as they are disproportionately affected by domestic and sexual violence, unmet family planning needs, increased risks of maternal morbidity and mortality, and consequently they face several SRH challenges [4-6]. It is crucial to gauge into the evidence of the effectiveness of SRH interventions in humanitarian contexts, to identify success lessons and forthcoming gaps by humanitarian organizations, governments, and other health care providers to build upon adequately tailored SRH programs, optimize service delivery, meet the needs, and improve the quality of services provision.

The minimum initial service package for reproductive health in crisis (MISP) is a priority set of interventions and activities required to be implemented at onset of any humanitarian crisis[7]. With its 13 reproductive health kits containing essential drugs and supplies for a three-month period, MISP offers a universal minimum standard of life-saving SRH interventions with its objectives (see Table 1) to facilitate coordination of SRH services, prevent and manage the consequences of sexual violence, reduce HIV transmission, minimize maternal/neonatal morbidity and mortality, reduce unintended pregnancies and unmet family planning needs, and plan for comprehensive SRH services as soon as the situation permits.. 
1. Ensure the health sector/cluster identifies an organization to lead implementation of the MISP. The lead SRH organization:

- Nominates an SRH Coordinator to provide technical and operational support to all agencies providing health services

- Hosts regular meetings with all relevant stakeholders to facilitate coordinated action to ensure implementation of the MISP

- Reports back to the health cluster, GBV sub-cluster, and/or HIV national coordination meetings on any issues related to MISP implementation.

- In tandem with health/GBV/HIV coordination mechanisms ensures mapping and analysis of existing SRH services

- Shares information about the availability of SRH services and commodities

- Ensures the community is aware of the availability and location of reproductive health services

2. Prevent sexual violence and respond to the needs of survivors:

- Work with other clusters especially the protection or gender-based violence sub-cluster to put in place preventative measures at community, local, and district levels including health facilities to protect affected populations, particularly women and girls, from sexual violence

- Make clinical care and referral to other supportive services available for survivors of sexual violence

- Put in place confidential and safe spaces within the health facilities to receive and provide survivors of sexual violence with appropriate clinical care and referral

3. Prevent the transmission of and reduce morbidity and mortality due to HIV and other STIs:

- Establish safe and rational use of blood transfusion

- Ensure application of standard precautions

- Guarantee the availability of free lubricated male condoms and, where applicable (e.g., already used by the population), ensure provision of female condoms

- Support the provision of antiretrovirals (ARVs) to continue treatment for people who were enrolled in an anti-retroviral therapy (ART) program prior to the emergency, including women who were enrolled in PMTCT programs

- Provide PEP to survivors of sexual violence as appropriate and for occupational exposure

- Support the provision of co-trimoxazole prophylaxis for opportunistic infections for patients found to have HIV or already diagnosed with HIV

- Ensure the availability in health facilities of syndromic diagnosis and treatment of STIs 


\section{Prevent Excess maternal and newborn morbidity and mortality:}

- Ensure availability and accessibility of clean and safe delivery, essential newborn care, and lifesaving emergency obstetric and newborn care (EmONC) services including:

- At referral hospital level: Skilled medical staff and supplies for provision of comprehensive emergency obstetric and newborn care (CEmONC) to manage

- At health facility level: Skilled birth attendants and supplies for uncomplicated vaginal births and provision of basic obstetric and newborn care (BEmONC)

- At community level: Provision of information to the community about the availability of safe delivery and EmONC services and the importance of seeking care from health facilities. Clean delivery kits should be provided to visibly pregnant women and birth attendants to promote clean home deliveries when access to a health facility is not possible

- Establish a 24 hours per day 7 days per week referral system to facilitate transport and communication from the community to the health center and hospital

- Ensure the availability of life saving post-abortion care in health centers and hospitals

- Ensure availability of supplies and commodities for clean delivery and immediate newborn care where access to a health facility is not possible or unreliable

\section{Prevent unintended pregnancies:}

- Ensure availability of a range of long-acting reversible and short-acting contraceptive methods (including male and female condoms and emergency contraception) at primary health care facilities to meet demand

- Provide information, including existing information, education, and communications (IEC) materials, and contraceptive counseling that emphasizes informed choice and consent, effectiveness, client privacy and confidentiality, equity, and non-discrimination

- Ensure the community is aware of the availability of contraceptives for women, adolescents, and men

\section{Plan for comprehensive SRH services:}

- Integrated into primary health care as soon as possible.

- Work with the health sector/cluster partners to address the six-health system building blocks: service delivery; health workforce; health information system; medical commodities; financing; and, governance and leadership.

Note: It is also important to ensure that safe abortion care is available, to the full extent of the law, in health centers and hospital facilities.

Hosting the second-highest proportion of refugees per capita in the world [1, 8, 9], Jordan is one of the countries most affected by the Syria crisis, with non-camp refugees mainly in Amman, Irbid and Mafraq. To intervene timely and responsively, it is critical to understand both the girls and women's needs for SRH services and respective factors preventing their access and use of such services. Previously published research showed that MISP implementation was inadequate, especially in urban settings, where Syrian refugees were dispersed amongst the local population [10,11]. A systematic literature review, which was conducted in 2019, highlighted the needs for more research to better comprehend the status of MISP 
implementation and the ability of host countries including humanitarian agencies to transition from MISP to comprehensive SRH service delivery among Syrian refugees in Jordan[12]. To be able to inform national SRH guidelines, policies, and programs in Jordan to improve SRH service delivery and respond to the needs of this refugee population, without compromising the needs of the general Jordanian population, more research was/is needed to evaluate and identify bottlenecks, lessons learnt and inform evidence-based SRH policies and guidance. After almost nine years of the protracted Syrian refugee humanitarian crisis, it was deemed essential to examine available evidence around the effectiveness of $\mathrm{SRH}$ interventions in Jordan for Syrian refugees, in order to inform humanitarian community including the government by identifying success lessons, essential gaps, bottlenecks and lessons learnt. In light of the above, we conducted an assessment aimed at exploring the current SRH situation and response for Syrian refugees in Jordan. The objectives of this assessment were to: 1) Assess the availability of SRH services, with a focus on MISP implementation and the ability to transition to comprehensive SRH service delivery among Syrian refugees in Jordan; and, 2) Explore facilitators and barriers impacting the availability, use of essential SRH services, and presence of national plans for the delivery of essential $\mathrm{SRH}$ services for Syrian refugees in Jordan.

\section{Methods}

This assessment used a mixed-methods approach, combining quantitative and qualitative research designs to evaluate the availability of SRH services, with a specific focus on the MISP among Syrian refugees in Jordan. The study was conducted in four governorates: Amman, Irbid, Zarqa and Mafraq. The assessment was conducted using a previously validated MISP/SRH survey[10,11]. The English version of the mentioned survey tool is available as a supplementary file alongside this paper. A stakeholders' mapping and analysis exercise was carried out to identify the most suited target population for this assessment. Consequently, $58 \mathrm{Kls}$ were interviewed who were from a diverse set of governmental, nongovernmental, international, and non-profit organizations. The interviews were conducted in four main governorates (Amman, Zarqa, Mafraq, and Irbid) from August to October 2018, given that they host the largest number of Syrian refugees in the county. The assessment questionnaire was translated and validated into Arabic and pilot-tested prior to field administration. Six research assistants were responsible for data collection, after receiving training. Data collection was carried real-time using tablets. Informed consents were obtained from all KIs, prior to each interview. The duration of each interview was approximately 60 minutes. A web-based survey tool (Harvest Your Data) was used for data collection, and analysis was done using SPSS-IBM (v.24). The qualitative data was analysed using content/thematic analysis.

\section{Results}

Findings from stakeholders' mapping and analysis indicated that the $58 \mathrm{KIs}$ interviewed were affiliated with a total of 15 different entities/agencies. The average years of the Kl's field experience was $10.5 \pm 8.3$ years. Most (91\%) of the Kls had a direct working experience with Syrian refugees in Jordan. Ministry of 
Health, UNFPA, and Jordan Health Aid Society (JHAS) Clinic were reported by $50 \%$ of the Kls as the key agencies responsible for coordinating SRH services provision to Syrian refugees (see Table 2 for more details). $71 \%$ of Kls $(n=41)$ stated having a list of the different agencies implementing $\mathrm{RH}$ response to Syrian refugees within their organization and provided that list to the research team; while, almost one third $(n=12)$ did not have or provide a copy of the list.

Table 2

Organizations reported as responsible for coordinating SRH services for Syrian refugees $(\mathrm{N}=58)$

\begin{tabular}{|lll|}
\hline Organization & Frequency & Percentage\% \\
\hline Ministry of Health & 12 & $20.7 \%$ \\
\hline UNFPA & 10 & $17.2 \%$ \\
\hline Jordan Health Aid Society (JHAS) Clinic & 8 & $13.8 \%$ \\
\hline Nour Al Hussein Foundation- NHF & 7 & $12.1 \%$ \\
\hline UNHCR & 5 & $8.6 \%$ \\
\hline Medecins Sans Frontieres (MSF) & 3 & $5.2 \%$ \\
\hline WHO & 3 & $5.2 \%$ \\
\hline Rawabi Al Balqa & 2 & $3.4 \%$ \\
\hline Others & 8 & $13.8 \%$ \\
\hline Total & 58 & 100.0 \\
\hline
\end{tabular}

About $45 \%$ of Kls $(n=26)$ had varying degrees of knowledge about MISP its associated objectives and activities. As for receiving training on MISP, 88.5\% $(n=23)$ indicated that they themselves received training on the MISP. However, of these, $56.5 \%(n=13)$ either did not remember or indicated that the last training they received was before 2017. The median number of participants that attended the last training on MISP (as indicated by them) was 25 participants. Only 59.3\% $(n=16)$ confirmed the commitment of their organizations in providing MISP training for their health professionals.

Similarly, 88.5\% $(n=23)$ confirmed that they ever engaged in providing some MISP-related RH services. The highest number of respondents who were engaged in the provision of some MISP-related services was indicated to be early on during the crisis i.e. in 2011 and 2012. 91.7\% KIs ( $n=22$ out of 24) explained that their roles were centred around providing: direct patients care, followed by planning for $\mathrm{RH}$ in emergency policy plans, introducing Disaster Risk Reduction (DRR) program within the organization, and MISP monitoring and evaluation.

Only $15 \mathrm{Kls}(25.9 \%)$ responded on the number of health personnel assigned to the implementation or provision of MISP within their organizations, which ranged from 2 personnel to as high as 100 staff 
members with a highly skewed distribution (median $=4$ staff members).

Results on knowledge of the different MISP objectives and priorities indicated similarly inadequate understanding and comprehension of the respondents. Many of the Kls were not able to identify the different MISP objectives correctly and were rather reliant only on the transferred knowledge gained from expertise and daily routine practices. Only 26 out of the $58 \mathrm{KIs}(44.8 \%)$ answered this section. Of which, 20-24 KIs were aware of some (but not all) of the MISP objectives, and two did not know any of them. "Preventing excess maternal and newborn morbidity and mortality" was the most commonly recognized MISP objective by $92.3 \% \mathrm{KIs}(\mathrm{n}=24)$, while "reducing HIV transmission" and "ensuring the health sector/cluster identifies an organization to lead the implementation of the MISP" were the least recognized objectives. Sources of information and knowledge about MISP was through training that was offered on MISP within the respondents' current organization followed by attending special dedicated courses (See Table 3). As for the six MISP priorities, 16-22 Kls were able to indicate all of them, and $4 \mathrm{KIs}$ were able to recognize any of them. "Ensuring availability of contraceptives in order to meet demand" was the most-reported priority, followed by "availability of STIs treatment" and "distribution of culturally appropriate menstrual protection material". "Ensuring availability of antiretrovirals (ARVs)" was the least reported. 
Table 3

Sources of information about MISP and knowledge about the objectives

\begin{tabular}{|c|c|c|c|c|c|c|c|}
\hline \multirow[t]{2}{*}{ Objectives } & & \multicolumn{5}{|c|}{ How did you hear about MISP } & \multirow{2}{*}{$\begin{array}{l}\text { Total } \\
\text { (out of } \\
58 \text { ) }\end{array}$} \\
\hline & & $1^{*}$ & $2^{\star}$ & $3^{*}$ & $4^{*}$ & $5^{\star}$ & \\
\hline \multirow{2}{*}{$\begin{array}{l}\text { Prevent excess maternal and } \\
\text { newborn morbidity and mortality }\end{array}$} & $\mathrm{n}$ & 18 & 3 & 3 & 5 & 4 & \multirow{2}{*}{$\begin{array}{l}24 \\
(41.4 \%)\end{array}$} \\
\hline & $\%$ & $75 \%$ & $12.5 \%$ & $12.5 \%$ & $20.8 \%$ & $16.6 \%$ & \\
\hline \multirow{2}{*}{$\begin{array}{l}\text { Plan for comprehensive SRH } \\
\text { services, integrated into primary } \\
\text { health care as the situation permits }\end{array}$} & $\mathrm{n}$ & 17 & 3 & 3 & 5 & 4 & \multirow{2}{*}{$\begin{array}{l}23 \\
(39.7 \%)\end{array}$} \\
\hline & $\%$ & $73.9 \%$ & $13 \%$ & $13 \%$ & $21.7 \%$ & $17.3 \%$ & \\
\hline \multirow{2}{*}{$\begin{array}{l}\text { Prevent and manage the } \\
\text { consequences of sexual violence }\end{array}$} & $\mathrm{n}$ & 15 & 4 & 3 & 5 & 3 & \multirow{2}{*}{$\begin{array}{l}22 \\
(37.9 \%\end{array}$} \\
\hline & $\%$ & 68.1 & $18.18 \%$ & $13.63 \%$ & $22.7 \%$ & $13.6 \%$ & \\
\hline \multirow{2}{*}{$\begin{array}{l}\text { Ensure the health sector/cluster } \\
\text { identifies an organization to lead } \\
\text { the implementation of the MISP }\end{array}$} & $\mathrm{n}$ & 14 & 3 & 3 & 5 & 3 & \multirow{2}{*}{$\begin{array}{l}20 \\
(34.5 \%)\end{array}$} \\
\hline & $\%$ & $70 \%$ & $15 \%$ & $15 \%$ & $25 \%$ & $15 \%$ & \\
\hline \multirow[t]{2}{*}{ Reduce HIV transmission } & $\mathrm{n}$ & 14 & 3 & 3 & 5 & 3 & \multirow{2}{*}{$\begin{array}{l}20 \\
(34.5 \%)\end{array}$} \\
\hline & $\%$ & $70 \%$ & $15 \%$ & $15 \%$ & $25 \%$ & $15 \%$ & \\
\hline \multicolumn{8}{|c|}{$1^{*}=$ Through my current organization/center/institute/agency } \\
\hline \multicolumn{8}{|c|}{$2^{*}=$ MISP Distance Learning Module online course } \\
\hline \multicolumn{8}{|l|}{$3^{*}=$ MISP course at a university } \\
\hline \multicolumn{8}{|l|}{$4^{*}=$ Experience in the field } \\
\hline
\end{tabular}

On the roles of organizations in engagement in MISP implementation, most agencies hosted/ facilitating regular meetings on MISP implementation $(n=18)$ followed by sharing information, and periodically participating in the meetings upon invitation.

As for the three MISP activities to prevent and manage the consequences of sexual violence (ensure community awareness about the benefits and availability of clinical services, make clinical care available to the survivors of rape, and put in place measures in place to protect women and girls from sexual violence), 18 to $21 \mathrm{KIs}$ had some knowledge. Regarding knowledge about the three MISP activities to reduce HIV transmission (ensures safe blood transfusion practice, makes free condoms available, and facilitates and enforces respect for standard precautions), 19 to $20 \mathrm{KIs}$ were aware. As for knowledge about the five MISP activities to prevent excess maternal and newborn morbidity and mortality, 18 to 22 KIs were aware of at least one of the five activities. "Ensuring the availability of both skilled birth attendants and supplies for normal births" and "Emergency Obstetric Comprehensive and newborn care 
services at referral hospitals" were the most recognised activities (recognized by 22 and 21 participants), while "distributing clean delivery kits to visibly pregnant women" was the least recognized activity (recognized by 18 participants). Finally, $24 \mathrm{Kls}$ had some knowledge pertaining to how the organization should transition towards the implementation of comprehensive SRH services as the situation permits. Examples included: coordinating ordering SRH equipment and supplies according to the demand, followed by collecting existing background data" and "assessing staff capacity, and identifying suitable sites for future service delivery. However, in each of these activities, the relevant knowledge/awareness of the KIs was limited, whereby, 4 to $8 \mathrm{KIs}$ did not know any of MISP activities pertaining to MISP objectives.

About half of the 58 respondents ( $31 \mathrm{KIs}$ ) confirmed the presence of a national Disaster Risk Reduction (DRR) agency or department, while only $17 \mathrm{KIs}$ were able to provide a specific name. Similarly, $24 \mathrm{Kls}$ reported that there is no DRR health policies or strategies at their organizations, while only $28 \mathrm{KIs}$ acknowledged that DRR policies and strategies targeted SRH and vulnerable populations in Jordan (see Fig. 1). Only 9 Kls indicated that it was either 2016, 2017, or 2018 when latest health risk assessment was conducted. Upon exploring the perceived SRH risks and potential barriers impeding a comprehensive SRH service provision for Syrian refugees, only $9 \mathrm{Kls}$ shared their thoughts. Of these, the following risks were indicated: maternal and neonatal deaths and inaccessibility and unaffordability to use SRH services, followed by increased domestic sexual violence, and lack of adequate antenatal care. Similarly, only 22 KIs responded to the section on the different community engagement approaches in early warning systems. The most commonly reported engagement approaches by these Kls included: partnership/ collaboration with local society/appropriate agencies ( $9 \mathrm{KIs})$, sharing community responsibility and accountability for policies and protocols, promoting family planning use ( $5 \mathrm{KIs})$ and engagement in awareness programs/health education (4 KIs).

With regards to the extent of national preparedness to implement SRH interventions during the early onset of Syrian crisis, 15 to $40 \mathrm{KIs}$, out of 47 respondents, (31.9-85.1\%) confirmed that their organization made prior preparations to launch at least one of the ten $\mathrm{SRH}$ programs in response to the Syrian humanitarian crisis. Out of the $10 \mathrm{SRH}$ programs implemented, the most commonly implanted ones include: maternal health (mentioned by $40 \mathrm{KIs}$ ), family planning ( $40 \mathrm{KIs})$ and condoms distribution (mentioned by $38 \mathrm{KIs}$ ), while the least implemented ones were provision of ARVs and access to safe blood (mentioned by $15 \mathrm{KIs}$ ) (See Table 4). International NGOs played a fundamental role in setting up the implementation of most of these SRH programs as compared to governmental organizations $(\mathrm{MOH})$. 44 out of $58 \mathrm{KIs}(75.9 \%)$ confirmed the organization of training workshops for their health workers (nurses, doctors, midwives, etc.) in Jordan to prepare for a humanitarian crisis. Data collection of SRH indicators for monitoring and evaluation of services was the most-reported activities, as it aimed at ensuring effective coordination and implementation of the different MISP objectives, while mapping, vetting and support of health facilities was the least recognized activity for the same purpose. Findings also indicated that only 20.7 to $22.4 \%$ of the needed supplies and kits were procured and pre-positioned prior to the crisis. Further, only $15 \mathrm{Kls}(25.9 \%)$ confirmed the presence of a logistics and commodities system to support the emergency distribution of health supplies, including SRH related supplies, while most of the Kls (> 45\%) were unmindful of any actions that have been undertaken for the same purpose. 
Table 4

Preparedness for SRH programs during the early onset of Syrian crisis according to the type of organization $(\mathrm{N}=47)$

\begin{tabular}{|c|c|c|c|c|c|c|}
\hline \multirow[t]{2}{*}{ SRH program } & & \multicolumn{3}{|c|}{ Type of Organization } & \multirow{2}{*}{$\begin{array}{l}\text { YES } \\
n(\%)\end{array}$} & \multirow{2}{*}{$\begin{array}{l}\text { NO } \\
\text { n (\%) }\end{array}$} \\
\hline & & Governmental & $\begin{array}{l}\text { Local } \\
\text { NGO }\end{array}$ & $\begin{array}{l}\text { International } \\
\text { NGO }\end{array}$ & & \\
\hline \multirow[t]{2}{*}{ Maternal health } & $\mathrm{n}$ & 6 & 14 & 20 & \multirow{2}{*}{$\begin{array}{l}40 \\
(85.1 \%)\end{array}$} & \multirow{2}{*}{$\begin{array}{l}7 \\
(14.9 \%\end{array}$} \\
\hline & $\%$ & $15 \%$ & $35 \%$ & $50 \%$ & & \\
\hline \multirow[t]{2}{*}{ Family planning } & $\mathrm{n}$ & 7 & 14 & 19 & \multirow{2}{*}{$\begin{array}{l}40 \\
(85.1 \%)\end{array}$} & \multirow{2}{*}{$\begin{array}{l}7 \\
(14.9 \%\end{array}$} \\
\hline & $\%$ & $17.5 \%$ & $35 \%$ & $47.5 \%$ & & \\
\hline \multirow[t]{2}{*}{ Condoms distribution } & $\mathrm{n}$ & 7 & 13 & 18 & \multirow{2}{*}{$\begin{array}{l}38 \\
(80.9 \%)\end{array}$} & \multirow{2}{*}{$\begin{array}{l}9 \\
(19.1 \%)\end{array}$} \\
\hline & $\%$ & $18.4 \%$ & $34.2 \%$ & $47.3 \%$ & & \\
\hline \multirow[t]{2}{*}{ Neonatal health } & $\mathrm{n}$ & 6 & 11 & 18 & \multirow{2}{*}{$\begin{array}{l}35 \\
(74.5 \%)\end{array}$} & \multirow{2}{*}{$\begin{array}{l}12 \\
(25.5 \%)\end{array}$} \\
\hline & $\%$ & $17.1 \%$ & $31.4 \%$ & $51.4 \%$ & & \\
\hline \multirow{2}{*}{$\begin{array}{l}\text { Sexual Transmitted Illnesses } \\
\text { (STIs) }\end{array}$} & $\mathrm{n}$ & 4 & 8 & 14 & \multirow{2}{*}{$\begin{array}{l}26 \\
(55.3 \%)\end{array}$} & \multirow{2}{*}{$\begin{array}{l}21 \\
(44.7 \%)\end{array}$} \\
\hline & $\%$ & $15.3 \%$ & $30.7 \%$ & $53.8 \%$ & & \\
\hline \multirow[t]{2}{*}{ Response to sexual violence } & $\mathrm{n}$ & 5 & 6 & 13 & \multirow{2}{*}{$\begin{array}{l}24 \\
(51.1 \%)\end{array}$} & \multirow{2}{*}{$\begin{array}{l}23 \\
(48.9 \%)\end{array}$} \\
\hline & $\%$ & $20.8 \%$ & $25 \%$ & $54.1 \%$ & & \\
\hline \multirow[t]{2}{*}{ Standard precaution } & $\mathrm{n}$ & 5 & 6 & 12 & \multirow{2}{*}{$\begin{array}{l}23 \\
(48.9 \%)\end{array}$} & \multirow{2}{*}{$\begin{array}{l}24 \\
(51.1 \%)\end{array}$} \\
\hline & $\%$ & $21.7 \%$ & $26 \%$ & $52.1 \%$ & & \\
\hline \multirow{2}{*}{$\begin{array}{l}\text { Prevention of sexual } \\
\text { violence }\end{array}$} & $\mathrm{n}$ & 5 & 5 & 13 & \multirow{2}{*}{$\begin{array}{l}23 \\
(48.9 \%)\end{array}$} & \multirow{2}{*}{$\begin{array}{l}24 \\
(51.1 \%\end{array}$} \\
\hline & $\%$ & $21.7 \%$ & $21.7 \%$ & $56.5 \%$ & & \\
\hline \multirow[t]{2}{*}{ Access to safe blood } & $\mathrm{n}$ & 4 & 5 & 9 & \multirow{2}{*}{$\begin{array}{l}18 \\
\text { (38.3\%) }\end{array}$} & \multirow{2}{*}{$\begin{array}{l}29 \\
(61.7 \%\end{array}$} \\
\hline & $\%$ & $22.2 \%$ & $27.7 \%$ & $50 \%$ & & \\
\hline \multirow[t]{2}{*}{ ARVs for continuing users } & $\mathrm{n}$ & 2 & 2 & 11 & \multirow{2}{*}{$\begin{array}{l}15 \\
(31.9 \%)\end{array}$} & \multirow{2}{*}{$\begin{array}{l}32 \\
(68.1 \%\end{array}$} \\
\hline & $\%$ & $13.3 \%$ & $13.3 \%$ & $73.3 \%$ & & \\
\hline
\end{tabular}

With respect to the onset of the SRH response, $28 \mathrm{KIs}(48.3 \%)$ indicated that the initiation of SRH services (in the context of the MISP) commenced within one to two weeks of the influx of the crisis, while $8 \mathrm{KIs}$ (13.8\%) reported that it commenced within three weeks or more, and more than one-third (20 KIs) did not know the exact date of when the SRH response was initiated. The extent of response of the $10 \mathrm{SRH}$ programs were consistent with the extent of extent of preparedness for those programs (See Fig. 2). 
Similar to SRH preparedness, the international NGOs played the main role in implementing the early SRH response programs during the Syrian crisis compared to governmental organizations $(\mathrm{MOH})$. Only $14 \mathrm{Kls}$ (14 Kls; $24.1 \%$ ) confirmed having a list of dedicated SRH staff in their agencies for any emergency response (with doctors, nurses, and midwives as the most common healthcare workers included in the list), while the rest did not know or mentioned not maintaining such list. Similarly, only $40 \%$ of the stakeholders (23 KIs) confirmed having dedicated funding for SRH response during the Syrian crisis, of these 20 could not specify the exact amount of funding either allocated or received. UNFPA and the $\mathrm{UNHCR}$ were indicated to be the main funding agencies, followed by $\mathrm{MOH}$ and $\mathrm{WHO}$. Almost $45 \%$ (26 KIs) indicated limited availability of SRH kits. The most available kits were 'condoms' and the least available ones were 'vacuum extraction during delivery' and 'blood transfusion'. As for the availability and distribution of clean delivery packages, $23 \mathrm{Kls}(39.7 \%)$ emphasized that the packages were available and distributed to Syrian refugee women. Further, $12 \mathrm{KIs}(46.2 \%)$ indicated that they did not perceive that the availability of SRH kits was adequately responsive to the needs of this crisis. The main reasons attributed to the shortages in SRH kits were financial challenges, inadequate administrative and logistics preparations, transportation challenges, inadequate implementation guidelines, and lack of equipped operating rooms. Coordination among the various humanitarian NGOs was variable, $6 \mathrm{Kls}(10.3 \%)$ indicated no coordination among while $9 \mathrm{Kls}(15.5 \%)$ reporting to have adequate degrees of coordination by participating in weekly $\mathrm{RH}$ meetings with other organizations. Almost half of the organizations (27 KIs) confirmed that they provided direct community access to information about the available SRH/MISP services, the benefits of seeking MISP services and where/how to locate them. This access was mainly facilitated by community health care workers and the distribution of IEC materials.

Having clear protocols to inform and guide the implementation of the MISP objectives coupled with setting up a lead SRH agency were perceived to be the two most important facilitators during the implementation of the SRH services, whereas inadequate funding, workforce, and supplies for response were the three main barriers reported (See Fig. 3). Further, adequate monitoring and evaluation, strengthening the capacities of the workforce to ensure adequate quality of SRH service delivery and care, regular and periodic capacity building activities, a holistic approach for responsive and coordinated SRH response, keeping accountability standards at the core center for evaluating and coordinating response, and strengthening in the areas of community engagement, community awareness, partnership and mobilization were perceived to be especially lacking and required immediate prioritization.

\section{Discussion}

The results of this assessment indicated that significant gaps exit about the knowledge of different MISP objectives and adequate implementation of these objectives coupled with the inability to transition to comprehensive delivery of SRH services remain problematic, even after almost ten years since the initial onset of this crisis. The respondents were unable to identify most of the objectives and priorities of the MISP as a package. Rather, their knowledge of the MISP objectives and priorities was as a subset of different types of SRH services that they provided direct care for (depending on their context). These gaps were further execrated because of the limited systematic availability and use of MISP/SRH services 
among Syrian refugees in Jordan. For example, stakeholders were unable to identify the prevention of HIV transmission as an essential objective of the MISP. It was evident that stakeholders limited their answers to only the objectives that align with their area of SRH service delivery at their organization. In spite of the national commitment to deliver comprehensive SRH services for Syrian refugees, actual implementation and response remains crippled and impacted by an array of factors, inclusive of limited capacity building around the MISP and the ability to transition to comprehensive service delivery, high staff turnover, and lack of funds for SRH projects and initiatives. The results of this assessments compared to earlier and previous MISP assessments in showed that the KIs in Jordan had more awareness and better knowledge about the different MISP objectives and activities, as be it the standard of SRH care in humanitarian emergencies, compared to previous assessments in other countries facing similar humanitarian crises [11, 13-17].

As far as the delivery of the different MISP services, findings supported previously reported data on the inadequate delivery, access to, and utilization of SRH services among refugees in Jordan [11, 18-25]. The antenatal care and SRH services provided as part of the national reproductive health programs, plans, and policies may have contributed to the delivery of MISP services without necessarily knowing about these activities as part of the MISP intervention package for emergency setting. The respondents were discussing the SRH services they provided without necessarily inter-relating and connecting between the routine or usual SRH care with MISP intervention and activities. Most of the stakeholders in this assessment were unable to identify the role of lead organizations responsible for the SRH response to the Syrian crisis. This can be a proxy indicator and result of the inadequate planning, coordination, and/or communication among the different agencies, institutions and organizations early onset and throughout the current Syrian refugee response in Jordan.

Further, it should be noted that any potential SRH services and interventions should not only take into account physical SRH needs of Syrian women and girls but should also and equally protect and respect their integrity and dignity during the delivery of these services. The results of this assessment indicated a sluggish progress in providing and maintaining such services especially for those that have been offered to a low socioeconomic status population, the refugees.

As for coordination and inter-sectoral approach, similar to previous studies [11, 26], most of the stakeholders emphasized not only the limited role of the $\mathrm{MOH}$ in this context but also considered the lack of intersectoral coordination to be problematic. Such differences when comparing the degrees of direct involvement of international humanitarian actors versus the government and that of the limited role of $\mathrm{MOH}$ Jordan were striking. This could be possibly attributed to the limited budget allocated by the national programs and the huge numbers of hosted refugees. In our findings, having clear protocols for the MISP and lead SRH agency were perceived to be the two main positive factors or facilitators to the effective implementation of SRH response in the crisis, whereas inadequate funding, workforce, and supplies for response were the three main barriers to the effective implementation of SRH response in the crisis. 
As for community engagement and involvement and its role in humanitarian response, the provision of SRH services is part of the national plan for all residents of Jordan, including Syrian refugee women and adolescents. However, when national campaigns were developed, the targeted communities and groups were decided with a focus on refugee camps, remote areas, and underprivileged population in rural areas while leaving out those Syrians living outside the camps and in the urban setting. This would explain why MISP information was communicated to communities but not in a proper and efficient manner.

In general, stakeholders identified several areas that need to be immediately prioritized, these included: setting up disaster risk reduction policies, offering regular SRH/ MISP training, improving coordination, increasing fund, improving referral system, and enhancing the skills of SRH providers to address the emergency obstetric care (EmOC) effectively.

\section{Conclusions}

This study attempted to provide an overview about the minimum initial service package for reproductive health in crisis (MISP) implementation, effectiveness of SRH interventions, and SRH challenges for e noncamp refugees in (Amman, Irbid, Zarqa, and Mafraq) Jordan, and to understand the critical needs of girls and women for SRH services coupled with factors preventing their utilization among Syrian refugees in the context of protracted displacement.

This study highlighted the importance of national coordination in the provision of SRH services and the need for the improvement of such coordination through a lead agency as well as the inclusion of SRH services provision in the available Disaster Risk Reduction strategies, policies, and response. Study findings also stress on developing a sustainable national plan for periodic SRH/MISP training on the MISP objectives and activities for SRH services providers from all sectors-governmental and nongovernmental-and transitioning to comprehensive SRH service delivery. This assessment also revealed the limited coordination among the various existent logistics support systems, including the need to improve stockpiling supplies, increase the number of SRH and newborn kits, and improve the quality of $\mathrm{SRH}$ services provided, all of which necessitate effective supply allocation and preparedness.

Developing a national plan for capacity building was another major area in need of focus, in order to ensure appropriate skills of SRH providers to effectively improve the quality of address SRH services delivery, including and most importantly basic and comprehensive EmOC. Conducting regular training coupled with refresher courses coupled with periodic institutional updates and revisions of MISP protocols are urgent priorities in order to improve the quality of SRH services delivered to Syrian women/adolescent girls refugees.

Further, lack of funding was a common concern for all the institutions interviewed in this assessment. This was often associated with the limited delivery of MISP/SRH services for the refugee communities.

\section{Recommendations:}


In light of the results of this assessment as well as based on the stakeholders' notes and comments, major recommendations that are essential to improve SRH service delivery and response for the Syrian refugees, and especially women and girls, in Jordan. These include: 1) Enhancing national coordination and inclusion of the provision of SRH services in the Disaster Risk Reduction policies, with $\mathrm{MOH}$, acting as the lead agency, in order: to exert a better leadership role in coordination and management, attention to quality of coordination to improve services provided, integrating and expanding SRH services to transition to comprehensive SRH services, positive changes in the communication mechanism, and more effective referral systems, particularly clear and straightforward policies for referring deliveries, high-risk pregnancies, rape cases, and sexual assaults; 2) Developing a sustainable national plan for regular and periodic training on the MISP objectives, and activities as well as on how to transition to comprehensive SRH service delivery; Likewise, developing a national plan for capacity building with a comprehensive strategy for capacity building at the national level, that includes both governmental and nongovernmental organizations, conducting more training and refresher courses, that are inclusive of a gender-based framework to allow to counsel and treat sexual violence survivors, transitioning to comprehensive SRH service delivery, and maintaining focus on the integration of MISP into SRH services with periodic updates and revisions of MISP protocols. 3) Developing a logistics system for distributing commodities and supplies inclusive of improving the stockpiling supplies, increasing the number of SRH and newborn kits, effective allocation of supplies and preparedness, and involving NGOs directly in supplies' distribution; 4) Increase funding specially allocated for: training on MISP, facilitating preparedness, improving coordination, improving referral systems, and developing the skills of SRH providers to address the Emergency Obstetric Care (EmOC) services effectively.

\section{Limitations}

This assessment has some limitations that need to be considered, these include low response rate and missing data attributed to the limited knowledge of the interviewed stakeholders on the essential SRH services as a package (MISP). Thus, the validity of some of the answers provided may not be adequately accurate. The data collection questionnaire was originally in English, which was translated into Arabic, back-translated, validated, and pilot-tested prior to this assessment. Despite these measures, the language may have impacted the comprehension of certain questions posed to the Kls. Further, although this assessment was an overall evaluation of SRH service delivery and response from a programmatic level, nine years after the Syrian crisis, it is likely that some changes could have occurred between the time when the field work for this assessment was carried out and when this paper was published. Hence, the situation could have been impacted by this lag period especially given the current impacts of the COVID-19 pandemic. Despite these limitations, we believe that the recommendations provided herein are noteworthy and still require immediate prioritization. This assessment provides an important overview and reflection about the needs for an adequate and comprehensive SRH response in the context of protracted humanitarian crisis and not just that for Syrian refugee crisis but beyond. It bears its own value, especially by highlighting the challenges impacting the adequate MISP implementation and the 
ability to transition to comprehensive SRH service delivery during protracted crises where funds, capacity building, procurements, coordination, and accountability are debilitating.

\section{List Of Abbreviations}

ARVs Antiretrovirals

DRR Disaster Risk Reduction

EMPHNET Eastern Mediterranean Public Health Network

EmOC Emergency Obstetric Care

JHAS Jordan Health Aid Society

HIV Human immunodeficiency virus

KIs Key Informants

MISP Minimum initial services package

MoH Ministry of Health

RH Reproductive Health

SRH Sexual and Reproductive Health

UNFPA United Nations Fund for Population Activities

UNHCR United Nations High Commissioner for Refugees

UNRWA United Nations Relief and Works Agency

WHO World Health Organization

\section{Declarations}

\section{Ethics approval and consent to participate}

This study was conducted after obtaining ethical clearance from the Institutional Review Board of the University of Jordan. Additionally, all ethical procedures, including obtaining informed consents, were in line with WHO guidelines for health research and were closely coordinated with the WHO Jordan Country Office and the Department of Sexual and Reproductive Health and Research (SRH) of WHO Geneva Office. Data were collected after getting oral and written consents from all key informants from the participating agencies. They were provided with detailed information on the study aims, procedures, and 
any potential risks and benefits due to their participation. To encourage honest and accurate responses, study participants were also assured that they had the full right to participate or withdraw from the study at any point during the interviews.

\section{Consent to publish}

Not applicable.

\section{Availability of data and materials}

All data generated and/or used and/or analyzed during this study are available from the corresponding author on reasonable request.

\section{Competing interests}

The authors declare that they have no competing interests. The authors alone are responsible for the views expressed in this article and they do not necessarily represent the views, decisions or policies of the funding bodies or institutions with which they are affiliated.

\section{Funding}

This work was funded by the Department of Sexual and Reproductive Health and Research (SRH), including the UNDP/UNFPA/UNICEF/WHO/World/Bank Special programme of research, development, and research training in human reproduction (HRP). The funders had no role in study design, data collection and analysis, decision to publish, or preparation of the manuscript.

\section{Authors' contributions}

Each author listed on the title page of this paper have made substantial contributions to the conception AND/OR design of the work; AND/OR the acquisition, analysis, AND/OR interpretation of results; AND/OR have drafted the work or substantively revised it. Additionally, all authors have approved the submitted version (and any substantially modified version that involves the author's contribution to the study); AND have agreed both to be personally accountable for their own contributions and to ensure that questions related to the accuracy or integrity of any part of the work, even ones in which the author was not personally involved, are appropriately investigated, resolved, and the resolution documented in the literature.

\section{Acknowledgements}

The authors would like to thank the Jordan Ministry of Health $(\mathrm{MOH})$ for providing their FETP (Field Epidemiology Training Program) residents to serve as field research assistants/data collectors and the WHO Jordan Country Office for facilitating the needed approvals. We would also like to thank the entire data collection team, including field research assistants and data collection facilitators, who tirelessly worked to collect the data for this study and all key informants who took part in this assessment. 


\section{References}

1. UNHCR. Global Trends: Forced displacement in 2018. 2018.

2. Askew I, Khosla R, Daniels U, Krause S, Lofthouse C, Say L. Sexual and reproductive health and rights in emergencies. Bull World Heal Organ 2016;94311. 2016;94(311).

3. Ivanova O, Rai M, Mlahagwa W, Tumuhairwe J, Bakuli A, Nyakato VN, et al. A cross-sectional mixedmethods study of sexual and reproductive health knowledge, experiences and access to services among refugee adolescent girls in the Nakivale refugee settlement, Uganda. Reprod Health [Internet]. 2019 Mar 19 [cited 2019 Mar 24];16(1):35. Available from: http://www.ncbi.nlm.nih.gov/pubmed/30890170.

4. Essaid A, Usta J, Shukri H, El-Gharaibeh Y, Abu Taleb H, Awwad N, et al. Gender Based Violence Against Women and Girls Displaced by the Syrian Conflict in South Lebanon and North Jordan: Scope of Violence and Health Correlates [Internet]. 2015 Apr. Available from: https://www.alianzaporlasolidaridad.org/wp-content/uploads/GBV-Against-Women-and-Girl-SyrianRefugees-in-Lebanon-and-Jordan-FINAL.pdf.

5. Asaf Y. Syrian Women and the Refugee Crisis: Surviving the Conflict, Building Peace, and Taking New Gender Roles. Soc Sci [Internet]. 2017;6(3):110. Available from: http://dx.doi.org/10.3390/socsci6030110.

6. UN Women. Gender-based violence and child protection among Syrian refugees in Jordan, with a focus on early marriage: Inter-agency assessment [Internet]. 2013. Available from: https://jordan.unwomen.org/en/digital-library/publications/2013/7/gender-based-violence-andchild-protection-among-syrian-refugees-in-jordan\#view.

7. IAWG. Inter-agency Field Manual on Reproductive Health in Humanitarian Settings [Internet]. 2018. Available from: http://iawg.net/resources2013/tools-and-guidelines/fieldmanual/.

8. UNHCR. FACT SHEET| Jordan [Internet]. 2019. Available from: https://reliefweb.int/sites/reliefweb.int/files/resources/72611.pdf.

9. UNHCR. Global, Trends: Forced displacement in 2019 [Internet]. 2019. Available from: https://www.unhcr.org/jo/13317-1-per-cent-of-humanity-displaced-unhcr-global-trends-report.html.

10. Doedens W, Giga N, Krause S, Onyango MA, Sami S, Stone E, et al. Reproductive Health services for Syrian refugees in Zaatari Refugee Camp and Irbid, Jordan [Internet]. 2013 [cited 2019 Oct 14]. Available from: https://data2.unhcr.org/en/documents/download/39302.

11. Krause S, Williams H, Onyango MA, Sami S, Doedens W, Giga N, et al. Reproductive health services for Syrian refugees in Zaatri Camp and Irbid City, Hashemite Kingdom of Jordan: an evaluation of the Minimum Initial Services Package. Confl Health [Internet]. 2015 [cited 2019 Mar 24];9(Suppl 1):S4. Available from: http://conflictandhealth.biomedcentral.com/articles/10.1186/1752-1505-9-S1S4.

12. Amiri M, El-Mowafi IM, Chahien T, Yousef H, Kobeissi LH. An overview of the sexual and reproductive health status and service delivery among Syrian refugees in Jordan, nine years since the crisis: a 
systematic literature review. Reprod Health [Internet]. 2020 Dec 1 [cited 2021 Feb 9];17(1):166. Available from: https://reproductive-health-journal.biomedcentral.com/articles/10.1186/s12978-02001005-7.

13. Women's Refugee Commission. Still in Need: Reproductive Health Care for Afghan Refugees in Pakistan [Internet]. 2003 [cited 2021 Apr 13]. Available from: https://www.refworld.org/docid/48aa83050.html.

14. Women's Refugee Commission. Life Saving Reproductive Health Care in Chad: Ignored and Neglected. 2004.

15. Women's Refugee Commission. Reproductive Health in an Emergency Assessment of the Minimum Initial Service Package in Tsunami-affected Areas in Indonesia. 2005.

16. Women's Refugee Commission. Reproductive Health Coordination Gap, Services Ad hoc: Minimum Initial Service Package (MISP) Assessment in Kenya [Internet]. 2008 [cited 2021 Apr 13]. Available from: https://www.womensrefugeecommission.org/wp-content/uploads/2020/04/ken_misp.pdf.

17. CARE, International Planned Parenthood Foundation (IPPF). Save The Children, Women's Refugee Commission. A Snapshot of Priority Reproductive Health Activities in Haiti: An Inter-agency MISP Assessment. 2010.

18. Al Rousan T, Schwabkey Z, Jirmanus L, Nelson BD. Health needs and priorities of Syrian refugees in camps and urban settings in Jordan: perspectives of refugees and health care providers. East Mediterr Heal J [Internet]. 2018;24(03):243-53. Available from: http://dx.doi.org/10.26719/2018.24.3.243.

19. UNHCR. Health Access and utilization Survey: Access to healthcare services among Syrian refugees in Jordan. [Internet]. 2018. Available from: https://data2.unhcr.org/en/documents/details/68539.

20. Samari G. Syrian Refugee Women's Health in Lebanon, Turkey, and Jordan and Recommendations for Improved Practice. World Med Heal Policy [Internet]. 2017;9(2):255-74. Available from: http://dx.doi.org/10.1002/wmh3.231.

21. Ay M, Arcos González P, Castro Delgado R. The Perceived Barriers of Access to Health Care Among a Group of Non-camp Syrian Refugees in Jordan. Int J Heal Serv [Internet]. 2016;46(3):566-89. Available from: http://dx.doi.org/10.1177/0020731416636831.

22. JCAP. Family Planning among Syrian Refugees in Jordan, March 2016 [Internet]. 2016. Available from: https://jordankmportal.com/resources/family-planning-among-syrian-refugees-in-jordan.

23. Juraibei M. Reproductive Health Services for Syrians Living Outside Camps in Jordan [Internet]. Higher Population Council; 2016. Available from: https://www.hpc.org.jo/sites/default/files/Reproductive Health Services for Syrians Living Outside Camps in Jordan.pdf.

24. Smith H. Syrian Refugee Women in Jordan: Family Planning Preferences and Barriers in a Host Community [Internet]. Independent Study Project (ISP) Collection. 2445. 2016. Available from: https://digitalcollections.sit.edu/isp_collection/2445. 
25. West L, Isotta-Day H, Ba-Break M, Morgan R. Factors in use of family planning services by Syrian women in a refugee camp in Jordan. J Fam Plan Reprod Heal Care [Internet]. 2017;43(2):96-102. Available from: http://dx.doi.org/10.1136/jfprhc-2014-101026.

26. Financial Tracking Service. Tracking Global Humanitarian Aid Flows, Consolidated Appeal, Syria Regional Refugee Response Plan (RRP) [Internet]. 2013. Available from: https://fts.unocha.org/appeals/423/flows?order=directional_property.

\section{Figures}

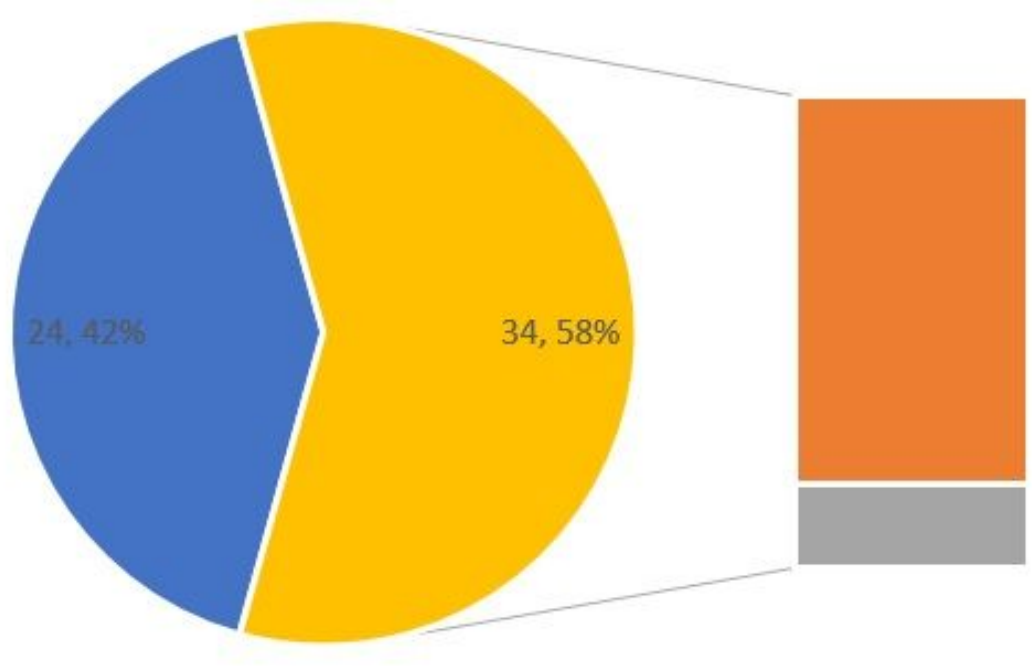

- There is no DRR health policies or $28,48 \%$ strategies and their components at their organization

- There are DRR health policies or strategies that included SRH and vulnerable populations

$6,10 \%$ - There are DRR health policies or strategies, but not for SRH and vulnerable populations

\section{Figure 1}

Availability of DRR health policies or strategies and their components $(\mathrm{N}=58)$ 


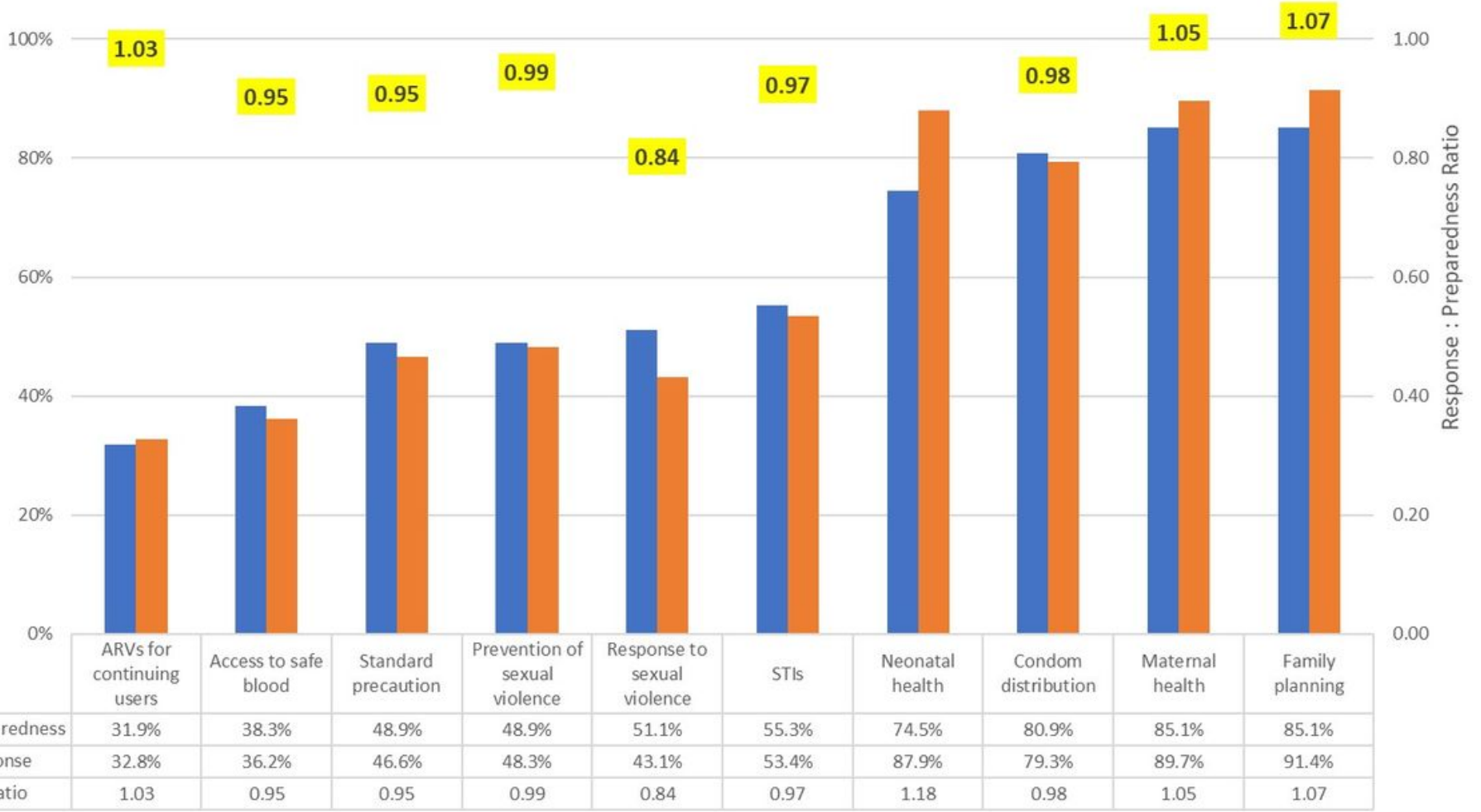

Figure 2

Comparison of the extent of preparedness and response to have SRH programs $(\mathrm{N}=100 \%)$ 


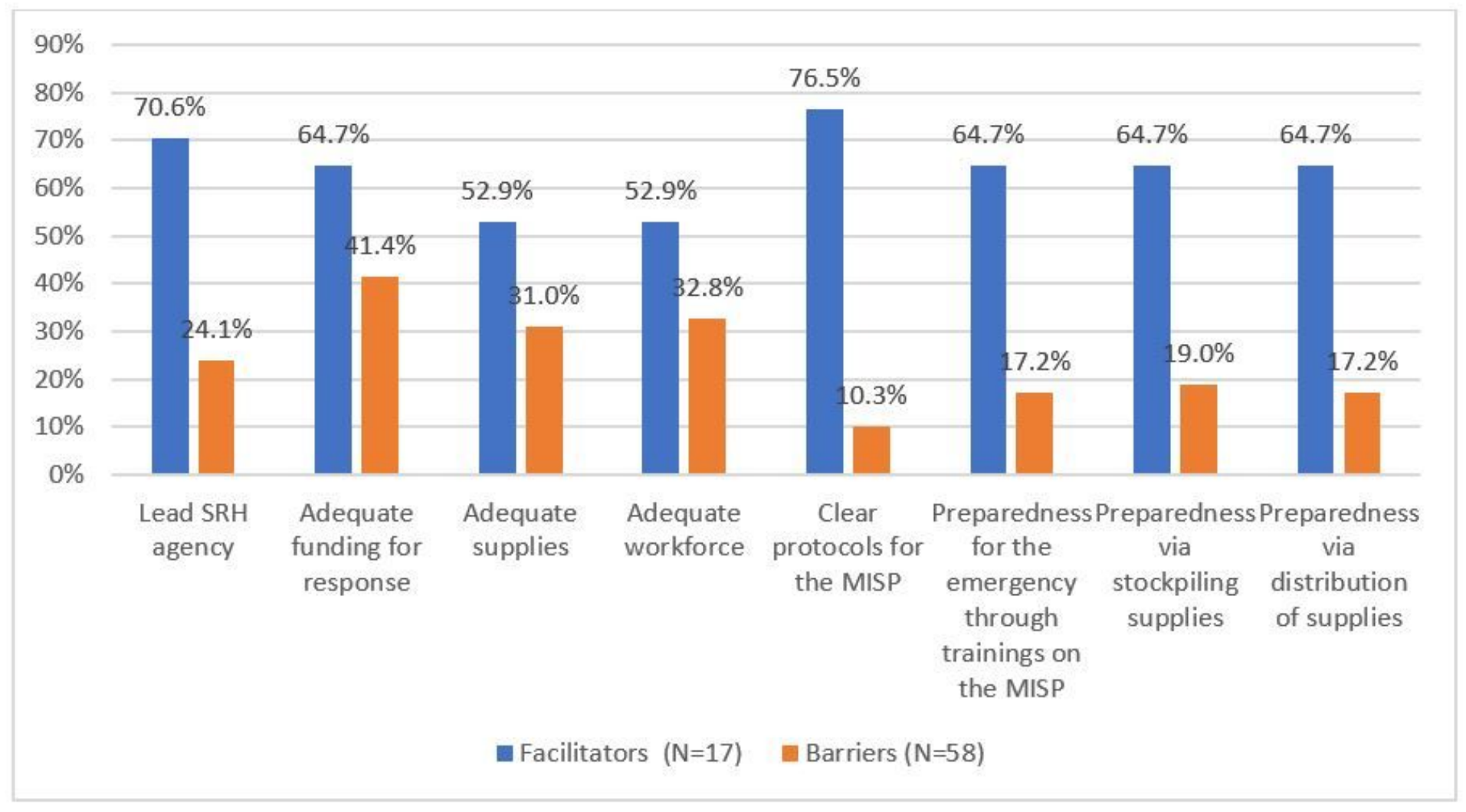

\section{Figure 3}

Factors Impacting the implementation of $\mathrm{SRH}$ response ( $\mathrm{N}=17$ for facilitators and $\mathrm{N}=58$ for barriers)

\section{Supplementary Files}

This is a list of supplementary files associated with this preprint. Click to download.

- AnnexSRHMISPAssessmentToolJordan.docx 